\title{
An Assessment of New Satellite Data Products for the Development of a Long-term Global Solar Resource at 10-100 km
}

\author{
Paul W. Stackhouse, $\mathrm{Jr}^{1}$, Patrick Minnis ${ }^{1}$, Richard Perez ${ }^{2}$, Manajit Sengupta ${ }^{3}$, Kenneth \\ Knapp $^{4}$, J. Colleen Mikovitz ${ }^{5}$, James Schlemmer ${ }^{2}$, Benjamin Scarino ${ }^{5}$, Taiping Zhang ${ }^{5}$, and \\ Stephen J. Cox ${ }^{5}$, \\ ${ }^{1}$ NASA Langley Research Center, Hampton, VA (USA) \\ ${ }^{2}$ SUNY-Albany, Albany, NY (USA) \\ ${ }^{3}$ National Renewable Energy Laboratory, Golden, CO (USA) \\ ${ }^{4}$ NOAA National Center for Environmental Information, Ashville, NC (USA) \\ ${ }^{5}$ Science Systems and Applications, Inc., Hampton, VA (USA)
}

\begin{abstract}
A project representing an effort to reprocess the NASA based solar resource data sets is reviewed. The effort represented a collaboration between NASA, NOAA, NREL and the SUNY-Albany and aimed to deliver a 10 $\mathrm{km}$ resolution, 3-hourly data set spanning from 1983 through near-present. Part of the project was to transition project capability to NREL for annual processing to extend data set. Due to delays in the key input project called ISCCP, we evaluate only Beta versions of this data set and also introduce the potential use of another NASA Langley based cloud data set for the CERES project. The CERES project uses these cloud properties to compute global top-of-atmosphere and surface fluxes at the $1 \times 1$ degree resolution. Here, we also briefly discuss these data sets in potential usage for solar resource benchmarking.
\end{abstract}

Keywords: Solar irradiance, solar resource, clouds, NASA, CERES, SSE, GEWEX SRB

\section{Introduction}

Considering the possibility of global climate change and the global competition for energy resources, there is a need to provide improved long-term global Earth surface solar resource information. During the last few years there has been a proliferation of solar resource information at high resolutions spanning 1998 - near present (e.g., Sengupta et al., 2014). However, there still is a need to improve the retrieval algorithms and expand the data sets in consistent and stable ways backwards in time far enough to obtain $20-30$ year data sets. This paper provides an update to a project previously described in Cox et al., (2013). The project represented a collaboration between the National Aeronautics and Space Administration (NASA), National Renewable Energy Laboratory (NREL), the State University of New York/Albany (SUNY) Atmospheric Science Research Center (ASRC) and the NOAA National Center for Environmental Information (NCEI, formally called National Climate Data Center, NCDC) to provide NREL with a global long-term advanced global solar mapping production system for improved depiction of historical solar resources and variability. An additional goal of the project is to provide a mechanism for NREL to continually update solar resource information on a global scale. The production system relies on the efforts of NOAA and NASA to completely reprocess the International Satellite Cloud Climatology Project (ISCCP) data set that provides satellite visible and infrared radiances together with retrieved cloud and surface properties on a 3-hourly basis beginning from July 1983 for all 8-10 km pixels archived by the project. The previous version of the ISCCP data provided this information for all the world's available geosynchronous satellite systems and 
NOAA's AVHRR data sets at a $30 \mathrm{~km}$ effective resolution. This information plus additional atmospheric information was used in NASA GEWEX Surface Radiation Budget project to produce the first global longterm maps for solar irradiance at a $1 \mathrm{x} 1$ degree resolution which became the basis for the NASA's Surface meteorology and Solar Energy web portal (SSE, Chandler et al., 2007, Stackhouse et al., 2007). Unfortunately, the new version of ISCCP has suffered substantial delays now exceeding 5 years and still is not ready for production. Therefore, existing data sets, entitled the ISCCP B1U (Rossow and Schiffer, 1996) and the NOAA NCEI GridSat-B1 (Knapp et al., 2011) were used to test the development of the algorithms and the eventual data production system. GridSat-B1 also contains all the world's geo-synchronous satellite radiances from $70^{\circ} \mathrm{N}$ to $70^{\circ} \mathrm{S}$. Now, a beta version of the ISCCP HX data set has been provided for testing purposes only. Here we evaluate the application of an updated version of the University of Albany SUNY (State University of New York) solar model (Perez et al.,2002) to this new ISCCP HX data to provide a first cut sample of the solar fluxes and their validation. We also introduce a new set of observations available to the solar community from the NASA Langley Research Center CERES (Clouds and Earth's Radiant Energy System) Mission. The CERES Mission is responsible for the CERES instrument that measures broadband solar and thermal infrared radiances that are directly related to the top-of-atmosphere radiative fluxes. The CERES instruments are on board satellites called Terra, Aqua and Suomi-NPP and are planned for future missions. As part of the CERES production system observations from imagers on board Aqua/Terra and all available geosynchronous satellites are processed to produce a comprehensive set of cloud data products. These products are used to estimate solar fluxes. In addition, the CERES project releases high quantities data products of surface solar related parameters at $1^{\circ} \times 1^{\circ}$ resolution. This paper presents a brief overview of the various available data products from NOAA and NASA used to estimate solar irradiances at the relatively high resolution of $10 \mathrm{~km}$ to the $100 \mathrm{~km}$ scale of the 1 degree data products.

\section{Preliminary Results with ISCCP High Resolution Precursors and HX Beta}

Previous papers detail the progressive results of using the ISCCP B1U and NOAA GridSat-B1 for solar irradiance estimation at $10 \times 10 \mathrm{~km}$ resolution. These early results were not made operational due to the plans to release the improved ISCCP HX data set that provides full radiance, cloud and surface retrievals. The effective resolution of this data set is $8-10 \mathrm{~km}$ depending upon the sensor to which radiances are subsampled and averaged to obtain. The data is available on a 3-hourly temporal basis. However, the ISCCP HX has been delayed now over 5 years due to the comprehensive nature of the revisions and complications in the production system development. Here, we have obtained the latest version of the ISCCP HX which is still officially in beta version and released only for evaluation purposes. For evaluation of the high resolution
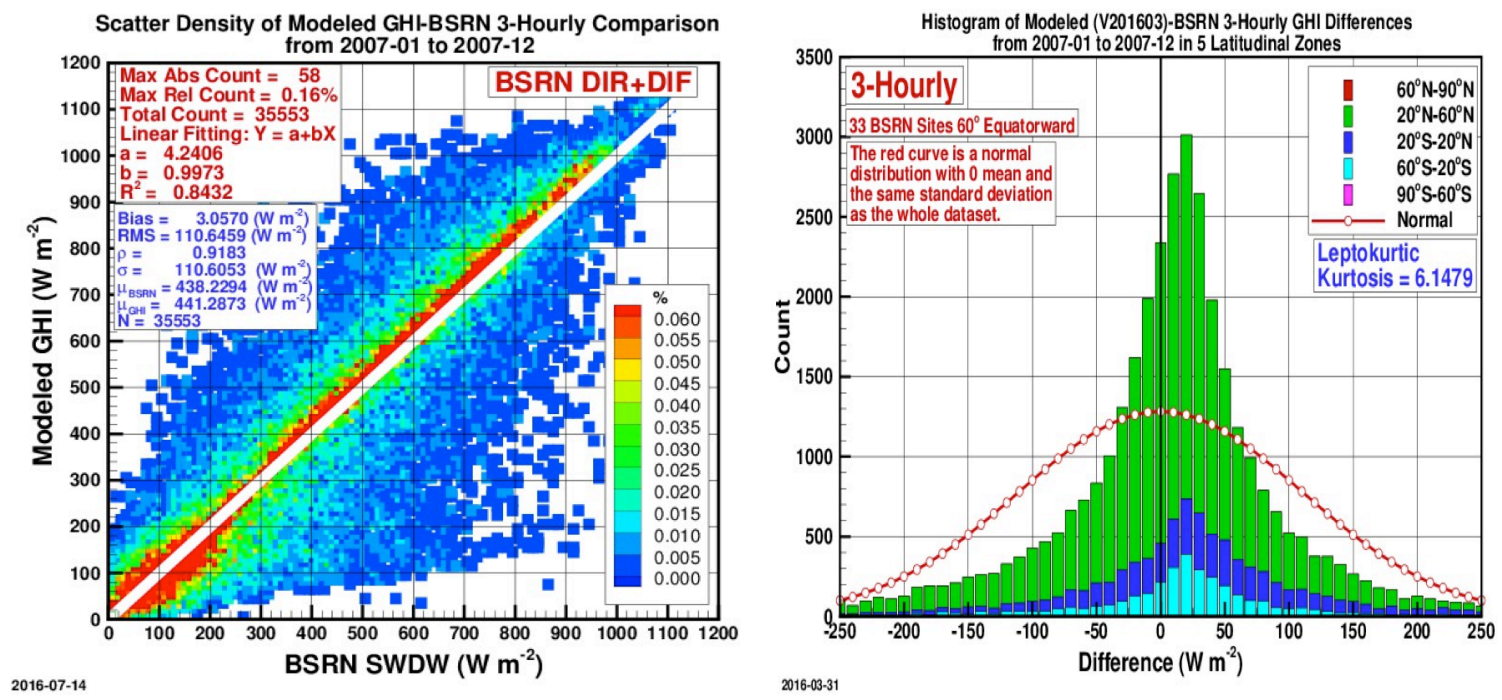

Figure 1: Comparison of 3-hourly solar irradiance estimates using ISCCP HX as input into the SUNY solar algorithm. A density scatter plot (left panel) shows the distribution of the differences with the colors corresponding frequency of differences in the given range as denoted on the legend. The right panel shows a histogram of the differences in a stacked bar chart with each color denoting the given latitude band as denoted in the legend. 
irradiances we have computed solar fluxes at the 3-hourly resolution for the world's BSRN (Baseline Surface Radiation Network, Ohmura et al., 1998) sites for the year 2007 using the SUNY algorithm (Perez et al., 2002). Figure 1 shows a density scatter plot of the various fluxes compared to the surface sites (left panel) and a histogram colored by latitude (right panel). We note that despite the relatively small value of the mean difference on the scatter plot, the histogram shows that the distribution of the differences shows a much large bias approaching $15-25 \mathrm{~W} \mathrm{~m}^{-2}$ for nearly all latitude zones. The SUNY and NASA LaRC teams are working understanding the source of these differences. The team has also tested an improved version of the radiative transfer based solar retrieval (improved relative to Stackhouse et al., 2011) using the ISCCP HX and found that at the 3-hourly fluxes gave overall mean difference and RMS of $-7.5 \mathrm{Wm}^{-2}$ and $85 \mathrm{~W} \mathrm{~m}^{-2}$ respectively at the $1 \times 1$ degree resolution and peaks of the distribution centered around $-5-5 \mathrm{~W} \mathrm{~m}^{-2}$. However, it is noted that the RMS differences are consistent with other existing data sets at the high temporal resolution and vary from $25-28 \%$.

\section{CERES Clouds Data Sets As a Global High Resolution Alternative}

As noted above CERES process global cloud products from geosynchronous and polar orbiting imagers (Minnis et al., 2008, 2011). The calibration of these instruments is improved using specialized methods that cross calibrate to the MODIS images. The cloud products begin around 2000 to correspond to the launch of the Terra satellite and extend to near present at a resolution of hourly at $4 \times 4 \mathrm{~km}$. The data sets include a complete set of cloud properties including cloud fraction, optical depth, cloud top and base information and the data is processed up to near-real time. Access to the cloud products and documentation is available at the web site: http://satcorps.larc.nasa.gov.

Owing to the delays in the ISCCP HX, we also initiated testing of these satellite cloud products for the estimation of solar fluxes using the improved LaRC model but adapted it to run at full pixel resolution. The solar fluxes were averaged to $25 \mathrm{~km}$ and the resulting hourly maps for the monthly averaged hour are shown in Figure 2. These maps show the surface solar fluxes as the sun angles change relative to the cloud fields at each hour. Comparisons of these fluxes to ARM (Atmospheric Radiation Measurement) program gave good results for most cases. However, there were a significant number of cases when there appeared to be a mismatch between the surface and satellite based estimates of solar fluxes. These cases are under investigation. Nevertheless, the success in processing the cloud data properties indicates that future solar resource maps could be derived from these inputs and further testing is planned.
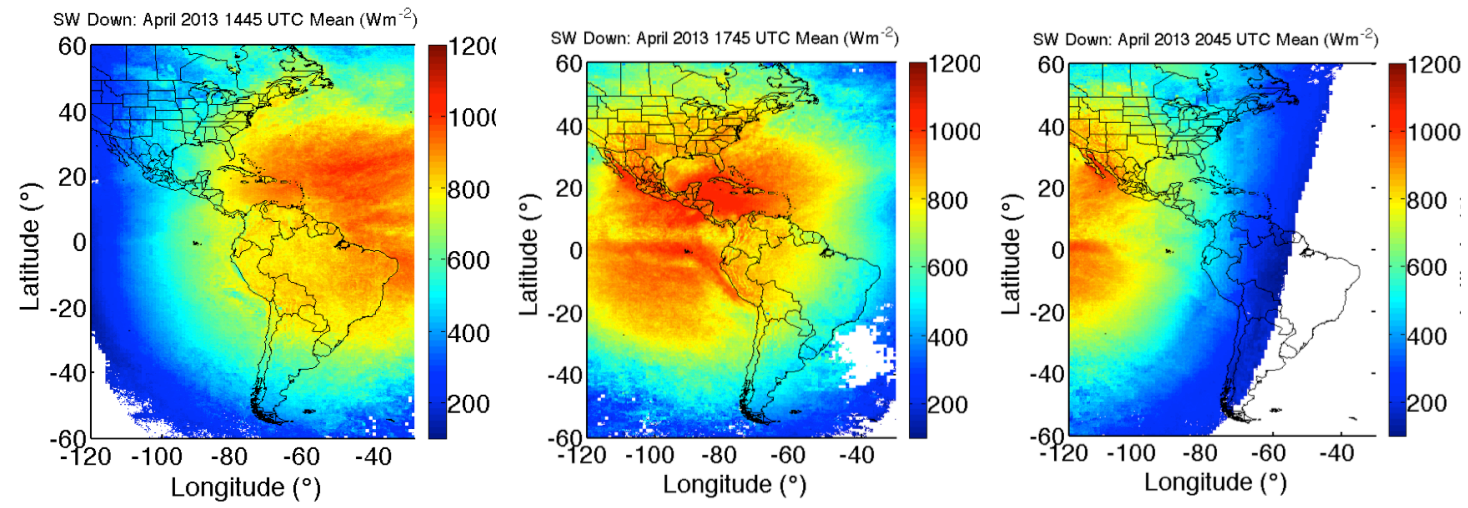

Figure 2: Maps for monthly averaged solar irradiances for 3 different hours (1445, 1745 and 2045 UT), after averaging to $25 \mathrm{~km}$. The solar fluxes are produced using the NASA LaRC CERES Cloud properties.

\section{CERES $1^{\circ} \times 1^{\circ}$ Data Sets for Long-term for Benchmarking and Long-term Variability}

The CERES mission is primarily responsible to produce global radiative flux data products at the top-ofatmosphere and at the surface (Wielicki et al., 1996). CERES produces multiple data sets relevant to the solar energy community. First, there is a CERES footprint level data product called Single Scanner Footprint (SSF). These data vary from $20 \mathrm{~km}$ at nadir to $50 \mathrm{~km}$ towards the limb. Complete cloud and surface 
properties are also included in these data products along with an estimate of the solar irradiance. However, it should be noted that these products are only provided at the overpass times from the Terra (10:30 local time) and Aqua (1:30 local time) satellites. Thus, they are really most useful for coincidence between surface measurements and overpass times. Temporally and spatially gridded data sets are also made available by the CERES mission. All the data products are gridded to the $1^{\circ} \times 1^{\circ}$ spatial resolution. However, the temporal resolution varies depending upon the data product use. For time series data within a few months of the present time, the data product entitled SYN1Deg is probably most applicable for the solar industry (Rutan et al., 2015). The data products include the total solar irradiance (or global horizontal irradiance, GHI) and the direct and diffuse components. The current version has data products from 3-hourly to monthly averaged all in UT time. For near-real time radiative fluxes (GHI only), the CERES FLASHFlux (Stackhouse et al., 2006, Kratz et al., 2012) provide daily average global fluxes up to 1 week behind real time. Lastly, the CERES Surface EBAF provides monthly averaged radiative fluxes that are scaled relative to TOA fluxes so that the net TOA fluxes agree with ocean heat content fluxes. These products are mostly used by climate modelers to evaluate the balance of energy at the TOA, are the most accurate in an absolute sense and have the best long-term stability. Table 1 shows the monthly averaged validation for the CERES SYN1Deg and Surface EBAF data products as adapted from Rutan et al (2015). Table 1 shows the validation of CERES Surface EBAF, SYN1Deg, and the GEWEX SRB (Stackhouse et al., 2011) data products (note that GEWEX SRB data products are used for the NASA SSE (Surface meteorology and Solar Energy) data products). The Surface EBAF data products produce radiative anomalies that are extremely well correlated with surface measurement anomalies (Kato et al., 2014).

Table 1: Comparisons of radiative fluxes to BSRN, ARM and ocean buoy measurements on monthly, daily and 3-hourly basis for the years 2000-2007 unless otherwise noted. This table is adapted from Rutan et al., 2015. All units are $\mathrm{W} \mathrm{m}^{-2}$ with \% in parentheses.

\begin{tabular}{|c|c|c|c|c|}
\hline Data set & $\begin{array}{c}\text { Monthly Mean } \\
\text { Bias (\%) }\end{array}$ & $\begin{array}{c}\text { Monthly mean } \\
\text { Std Dev (\%) }\end{array}$ & $\begin{array}{c}\text { Daily mean } \\
\text { Std Dev (\%) }\end{array}$ & $\begin{array}{c}\text { 3-hourly Std } \\
\text { Dev (\%) }\end{array}$ \\
\hline CERES Surface EBAF & $1.0(0.0)$ & $12.4(6.1)$ & -- & -- \\
\hline CERES SYN1Deg & $3.0(1.5)$ & $11.6(5.7)$ & $31.0(15.3)$ & $55.5(27.5)$ \\
\hline CERES FLASHFlux $^{1}$ & $-3.5(-1.8)$ & $20.5(10.7)$ & $33.8(18.1)$ & -- \\
\hline GEWEX SRB (SSE) $^{2}$ & $2.0(1.0)$ & $21.2(10.5)$ & $37.6(18.6)$ & $72.2(35.7)$ \\
\hline ERA-Interim $^{2}$ & $7.4(3.7)$ & $16.8(8.3)$ & -- & -- \\
\hline
\end{tabular}

${ }^{1}$ FLASHFlux validation from the year 2015 using same set of surface sites.

2 ERA-Interim has finer temporal resolution, but it wasn't downloaded here.

All the CERES data products are available via the web page http://ceres.larc.nasa.gov and by using the link data access to browse and subset various data products according to user needs. It should also be noted that the NASA LaRC POWER (Prediction of Worldwide renewable Energy Resource) project prepares the daily averaged FLASHFlux data products together with surface meteorological data as a time series accessible at one latitude/longitude location at a time via the web portal: http://power/larc.nasa.gov and under the "Sustainable Buildings" link.

\section{Summary and Conclusions}

This paper described the progress made toward using NASA/NOAA data sets to provide long-term solar resource information using both the NASA GEWEX SW model and SUNY-Albany models. The latter has been tested for use with a beta version of the new ISCCP H series data products. These products are planned for operational production as a climate data record at the NCEI, but continued delays in the data product release have slowed finalization of the algorithm testing and evaluation. However, the preliminary results at the $10 \mathrm{~km}$ resolution gave results comparable to currently available methods at least for the total shortwave flux (as know as the global horizontal irradiance or GHI). This paper also showed some very preliminary results using the GEWEX SW model and high resolution cloud properties processed by the CERES Clouds 
group at NASA LaRC. These data products are already available to the public via the web site noted above. Lastly, formal CERES data products, produced using those cloud products, were introduced to the solar community. Although, these data products are $1^{\circ} \times 1^{\circ}$ horizontal resolution, the validation of the data products shows excellent agreement from daily to monthly temporal scales. The length of these records should prove useful to the solar community for benchmarking purposes.

\section{References}

Chandler, W. S., P. W. Stackhouse, Jr., C.H. Whitlock, J.M. Hoell, D. Westberg, T. Zhang, 2007. NASA's Surface Meteorology and Solar Energy Web Portal (Release 6.0). Proceedings of Solar 2007, American Solar Energy Society Meeting, Cleveland, OH, 7 - 12 July.

Cox, Stephen. J., Stackhouse, P.W., Jr., W.S. Chandler, J.M. Hoell, T. Zhang, D.J. Westberg, C.H. Whitlock, R. Perez, C. Hemker, J. Schlemmer, D. Renne, M. Sengupta, J. Bates, and K. Knapp, 2013. Progress towards deriving an improved long-term global solar resource. Proceedings of the Solar 2013 (American Solar Energy Society). Baltimore, MD, 16-20 April.

Kato, S., N. G. Loeb, F. G. Rose, D. R. Doelling, D. A. Rutan, T. E. Caldwell, L. Yu, and R. A. Weller, 2013. Surface irradiances consistent with CERES-derived top-of-atmosphere shortwave and longwave irradiances. J. Climate, 26, 2719-2740, doi:10.1175/JCLI-D-12-00436.1.

Knapp, K. and Coauthors, 2011. Globally gridded satellite observations for climate studies. Bull. Of Amer. Meteor. Soc., 92, 893-907, DOI: http://dx.doi.org/10.1175/2011BAMS3039.1

Kratz, D. P., P. W. Stackhouse, Jr., S. K. Gupta, A. C. Wilber, P. Sawaengphokhai, and G. R. McGarragh, 2014. The Fast Longwave and Shortwave Flux (FLASHFlux) data product: Single Scanner Footprint Fluxes. J. Appl. Meteor. and Climatol., 53, 1059-1079.

Minnis, P., L. Nguyen, R. Palikonda, P. W. Heck, D. A. Spangenberg, D. R. Doelling, J. K. Ayers, W. L. Smith, Jr., M. M. Khaiyer, Q. Z. Trepte, L. A. Avey, F.-L. Chang, C. R. Yost, T. L. Chee, and S. SunMack, 2008: Near-real time cloud retrievals from operational and research meteorological satellites. Proc. SPIE Remote Sens. Clouds Atmos. XIII, Cardiff, Wales, UK, 15-18 September, 7107-2, 8 pp., ISBN: 9780819473387.

Minnis P., S. Sun-Mack, D. F. Young, P. W. Heck, D. P. Garber, Y. Chen, D. A. Spangenberg, R. F. Arduini, Q. Z. Trepte, W. L. Smith, Jr., J. K. Ayers, S. C. Gibson, W. F. Miller, G. Hong, V. Chakrapani, Y. Takano, K.-N. Liou, Y. Xie, and P. Yang, 2011. CERES Edition-2 cloud property retrievals using TRMM VIRS and Terra and Aqua MODIS data--Part I: Algorithms. IEEE Trans. Geosci. Remote Sens., 49, 4374-4400.

Ohmura, A., and Coauthors, 1998. Baseline Surface Radiation Network (BSRN/WCRP): New precision radiometry for climate change research. Bull. Amer. Meteor. Soc., 79, 2115-2136, doi:10.1175/15200477(1998)079,2115:BSRNBW.2.0.CO;2.

Perez, R.; Ineichen, P.; Moore, K. Kmiecikm, M. Chain, C. George, R. Vignola, F., 2002. A New Operational Satellite-to-Irradiance Model. Solar Energy, 73 5, pp. 307-317.

Sengupta, M., Habte, A., Gotseff, P., Weekley, A., Lopez, A., Anderberg, M., Molling, C., Heidinger, A., 2014. Physics-Based GOES Product for Use in NREL's National Solar Radiation Database: Preprint. 6 pp.; NREL Report No. CP-5D00-62776.

Stackhouse, P.W., Jr., D. P. Kratz, G.R. McGarragh, S.K. Gupta and Erika B. Geier, 2006. Fast Longwave and Shortwave Radiative Flux (FLASHFlux) Products from CERES and MODIS Measurements. In Proceedings of the 12th conference on atmospheric radiation. Madison, WI, July 10-14.

Stackhouse, Paul W., Jr., S. K. Gupta, Stephen J. Cox. Taiping Zhang, J. Colleen Mikovitz, and Laura M. Hinkelman, 2011. The NASA/GEWEX Surface Radiation Budget Release 3.0: 24.5-Year Dataset. GEWEX News, V 21, No. 1, p10-12, February.

Wielicki, B. A., B. R. Barkstrom, E. F. Harrison, R. B. Lee III, G. L. Smith, and J. E. Cooper, 1996. Clouds and the Earth's Radiant Energy System (CERES): An Earth Observing System experiment. Bull. Amer. Meteor. Soc., 77, 853-868, doi:10.1175/1520-0477(1996)077,0853:CATERE.2.0.CO;2. 
